\title{
Editors of the Polish Journal of Neurology and Neurosurgery announce the first issue featuring a Leading Topic
}

\author{
Zbigniew K. Wszolek ${ }^{1}$, Łukasz Stolarczyk ${ }^{2}$, Jarosław Sławek ${ }^{3}$ \\ ${ }^{1}$ Co-Editor-in-Chief, Department of Neurology, Mayo Clinic, Jacksonville, Florida, United States \\ ${ }^{2}$ Journal Administrator, Via Medica ${ }^{\mathrm{TM}}$, Gdansk, Poland \\ ${ }^{3}$ Co-Editor-in-Chief, Department of Neurology and Psychiatry, Medical University of Gdansk, Gdansk, Poland
}

(Neurol Neurochir Pol 2021; 55 (2): 119)

As announced last year, and enthusiastically supported by the Editorial Board members [1], in this issue of the Polish Journal of Neurology and Neurosurgery (Neurologia $i$ Neurochirurgia Polska), we present the first Leading Topic (a compilation of several articles dealing with a common theme) with an accompanying Invited Editorial. We hope that this new feature will be welcomed by our readers. We encourage you to let us know your thoughts regarding any improvements you would like to see, and to contact us if you would like to contribute to a future Leading Topic. We plan at least one issue (preferably two) per year that features a Leading Topic.

\section{References}

1. Wszołek ZK, Stolarczyk Ł, Sławek J. Further publication enhancements discussed during the current Editorial Board meeting of the Polish Journal of Neurology and Neurosurgery (Neurologia i Neurochirurgia Polska). Neurol Neurochir Pol. 2020; 54(5): 361-363, doi: 10.5603/ PJNNS.2020.0085, indexed in Pubmed: 33135150. 